\title{
Plasmin Inhibition of Platelet Function and of Arachidonic Acid Metabolism
}

\author{
Andréw I. Schafer and Burt Adelman \\ Hemostasis Unit and Hematology Division, Department of Medicine, Brigham and \\ Women's Hospital, and Harvard Medical School, Boston, Massachusetts 02115
}

\begin{abstract}
To study interactions between platelets and the fibrinolytic system, we examined the effects of human plasmin on human platelets washed by gel filtration. Plasmin concentrations that did not affect platelet shape change, release, or aggregation ( $<1.0$ caseinolytic units $[\mathrm{CU}] / \mathrm{ml})$ caused a dose- and timedependent inhibition of platelet aggregation in response to thrombin, ionophore A23187, and collagen. Complete loss of aggregation occurred at $0.1-0.5 \mathrm{CU} / \mathrm{ml}$ of plasmin. In a parallel dose-dependent manner, plasmin likewise inhibited thrombin, ionophore, and collagen-stimulatêt thromboxane $\mathbf{B}_{\mathbf{2}}$ production. In contrast, neither aggregation nor thromboxane $\mathbf{B}_{\mathbf{2}}$ formation induced by arachidonate was inhibited by plasmin pretreatment of the platelets. Plasmin blocked the thrombininduced release of $\left.{ }^{3} \mathbf{H}\right]$ arachidonic acid from platelet membrane phospholipids and the thrombin-induced platelet oxygen burst. However, plasmin did not inhibit the arachidonate-induced oxygen burst. Inhibition of arachidonic acid release by plasmin was not mediated by increase in platelet cyclic AMP. These results suggest that plasmin inhibits platelet function, at least in part, by blocking the mobilization of arachidonic acid from membrane phospholipid pools. The effects of plasmin on platelets may contribute to the hemostatic abnormalities seen in pathologic and pharmacologic fibrinolysis.
\end{abstract}

\section{Introduction}

After vascular injury, platelet activation and thrombin generation occur by a reciprocally amplifying mechanism which results in rapid thrombus formation. As fibrin formation occurs, the fibrinolytic system becomes activated to promote fibrin dissolution. However, the role of platelets in fibrinolysis is not clearly understood. Platelets can support and localize fibrinolysis by facilitating clot retraction (1-4), binding plasminogen, and potentiating plasminogen activation (5). Plasmin may also affect platelet function. Streptokinase injection into rabbits causes transient thrombocytopenia, prolongation of the bleeding time, in vivo platelet degranulation and release, and inhibition of the in vitro aggregation response to collagen (6). Platelets treated in vitro with plasmin have a shortened survival

Dr. Schafer is an Established Investigator of the American Heart Association. Dr. Adelman is the recipient of National Heart, Lung, and Blood Institute Clinical Investigator Award HL-01051. Reprint requests should be addressed to Dr. Schafer, Brigham and Women's Hospital, 75 Francis St., Boston, MA 02115.

Received for publication 3 July 1984 and in revised form 27 September 1984.

J. Clin. Invest.

(c) The American Society for Clinical Investigation, Inc. 0021-9738/85/02/0456/06 \$1.00

Volume 75, February 1985, 456-461 when infused into rabbits, presumably because of plasmininduced alterations in platelet membrane glycoproteins (7). Furthermore, the shortening of platelet survival during continuous vessel wall injury in the rat can be reversed by the antifibrinolytic agent epsilon aminocaproic acid (8). Recently, we have shown that plasmin treatment of platelets in vitro leads to a loss of platelet membrane glycoprotein Ib, a surface receptor for von Willebrand's factor, with an associated inhibition of ristocetin-induced platelet agglutination (9). Previous in vitro studies on the direct effects of plasmin on platelet function have shown that high concentrations of plasmin stimulate aggregation and release, and that prolonged exposure of platelets to plasmin results in inhibition of thrombin- and collagen-induced aggregation $(6,10)$. These results have been considered to indicate that plasmin induces the release of and then the digestion of platelet fibrinogen, causing a subsequent loss of platelet sensitivity to aggregating agents (6).

This study investigates in detail the function of human platelets exposed to human plasmin and, specifically, examines for the first time the effects of plasmin on platelet arachidonic acid metabolism. We have found that plasmin, at concentrations considerably lower than previously studied, causes a dose- and time-dependent inhibition of platelet aggregation which is associated with a marked impairment of thromboxane formation. Plasmin was found to specifically inhibit endogenous arachidonic acid mobilization from platelet membrane phospholipid pools.

\section{Methods}

Preparation of platelets. Venous blood anticoagulated with $13 \mathrm{mM}$ sodium citrate was obtained from volunteers who had not ingested aspirin or other medications known to interfere with platelet function for at least $10 \mathrm{~d}$ before donation. Blood was centrifuged at $160 \mathrm{~g}$ for $10 \mathrm{~min}$ to obtain platelet-rich plasma (PRP) ${ }^{1}$. Platelets were separated from plasma by gel filtration by applying PRP to a column of Sepharose 2B. The platelets were eluted with a modified Tyrode's buffer containing $130 \mathrm{mM} \mathrm{NaCl}, 9 \mathrm{mM}$ sodium bicarbonate, $6 \mathrm{mM}$ dextrose, $10 \mathrm{mM}$ sodium citrate, $10 \mathrm{mM}$ Trizma base, $0.8 \mathrm{mM}$ $\mathrm{KH}_{2} \mathrm{PO}_{4}, 3 \mathrm{mM} \mathrm{KCl}, 0.9 \mathrm{mM} \mathrm{MgCl}, 0.5 \%$ albumin (for aggregation experiments), and $0.04 \mathrm{U} / \mathrm{ml}$ apyrase (except for serotonin release experiments), $\mathrm{pH}$ 7.3. Platelet counts were determined in a counter (model F; Coulter Electronics, Inc., Hialeah, FL).

Plasmin preincubation of platelets. Plasmin was dissolved in 10 $\mathrm{mM}$ Tris, $150 \mathrm{mM} \mathrm{NaCl}, \mathrm{pH} \mathrm{7.4}$, and stored in aliquots of 1 caseinolytic unit (CU)/40 $\mu \mathrm{l}$ at $-40^{\circ} \mathrm{C}$. CU were defined according to Squouris et al. (11): $1 \mathrm{CU}$ equals 1.14 Committee on Thrombolytic Agents units (12). Gel-filtered suspensions of platelets were incubated with plasmin at $37^{\circ} \mathrm{C}$ in a shaking water bath as described below. At the end of the appropriate preincubation periods, plasmin was inactivated with aprotinin before the addition of a stimulating agent (throm-

1. Abbreviations used in this paper: CU, caseinolytic units; HPLC, high-performance liquid chromatography; $\mathrm{PGE}_{1}$ and $\mathrm{PGI}_{2}$, prostaglandins $E_{1}$ and $I_{2}$; PRP, platelet-rich plasma; TIU, trypsin inhibitor units; $\mathrm{TXB}_{2}$, thromboxane $\mathrm{B}_{2}$. 
bin, ionophore A23187, collagen, or arachidonate). The concentration of aprotinin added was always in excess of the amount needed to totally inhibit plasmin activity as determined in an S-2288 chromogenic substrate assay following the manufacturer's method (13). The assay was performed at $37^{\circ} \mathrm{C}$ in a spectrophotometer equipped with a recording chart (model 2400; Gilford Instrument Laboratories, Inc., Corning Glass Works, Oberlin, $\mathrm{OH}$ ). Kinetic data supplied by the manufacturer indicate that, for a substrate concentration of $1 \times 10^{-3}$ $\mathrm{mol} / \mathrm{liter}$ and a plasmin concentration of $4 \times 10^{-9} \mathrm{~mol} / \mathrm{liter}, \Delta \mathrm{A} / \mathrm{min}$ at $405 \mathrm{~nm}$ is 0.042 . One CU plasmin equals $\sim 0.45 \mathrm{nmol}$ plasmin. Aprotinin was likewise added before platelet stimulation in control reactions that were preincubated with no plasmin.

Platelet aggregation. Aliquots of $0.4 \mathrm{ml}$ of gel-filtered platelets were added to cuvettes containing $\mathrm{CaCl}_{2}(3 \mathrm{mM}$, final concentration). Aggregation was monitored using a standard nephelometric method (14) in a dual-channel aggregometer (Payton Associates, Inc., Buffalo, NY).

Platelet serotonin release. PRP was incubated with $3.4 \mu \mathrm{M}$ $\left[{ }^{14} \mathrm{C}\right]$ serotonin, gel-filtered, and serotonin release was measured by a modification of the method of Jerushalmy and Zucker (15). Reactions were terminated with formalin (1.5\%, final concentration) to stop further release or re-uptake of serotonin (16). Samples were immediately centrifuged at $8,700 \mathrm{~g}$ for $3 \mathrm{~min}$ in a microfuge (model B; Beckman Instruments, Inc., Spinco Div., Palo Alto, CA), and supernatants were counted for released radioactivity.

Radioimmunoassay of thromboxane $B_{2}\left(T X B_{2}\right)$. Immediately after 4-min reactions with the appropriate stimuli, platelet suspensions were centrifuged at $8,700 \mathrm{~g}$ for $3 \mathrm{~min}$. The amount of $\mathrm{TXB}_{2}$ in the supernatants was determined by standard radioimmunoassay with phosphate-gelatin buffer $(50 \mathrm{mM}$ potassium biphosphate, $0.14 \mathrm{M} \mathrm{NaCl}$, and $0.1 \%$ gelatin, $\mathrm{pH} 7.4$ ), a 1:2,000 dilution of $\mathrm{TXB}_{2}$ antiserum, and $10,000 \mathrm{dpm}\left[{ }^{3} \mathrm{H}\right] \mathrm{TXB}_{2}$. After overnight incubation at $4^{\circ} \mathrm{C}$, charcoalcoated dextran was used to separate antibody-bound from unbound radioligand.

Oxygen consumption. Polarographic measurements were made with an oxygen monitor (model 53; Yellow Springs Instrument Co., Yellow Springs, $\mathrm{OH}$ ) equipped with a Clark-type oxygen sensor (model 5331; Yellow Springs Instrument Co.). The electrode was fitted to a waterjacketed cell (OX-15253; Gilson Medical Electronics, Middleton, WI) connected to a circulator (K-2/RD; Lauda Div., Brinkmann Instruments, Inc., Westbury, NY) maintained at $37^{\circ} \mathrm{C}$. At $37^{\circ} \mathrm{C}$, a $0.13 \mathrm{M} \mathrm{NaCl}$ solution was assumed to contain $400 \mathrm{nAtoms} \mathrm{O}_{2} / \mathrm{ml}$ at equilibrium with room air. Full-scale deflection of the instrument was adjusted to correspond to this $\mathrm{O}_{2}$ content (17).

Release of $\left[{ }^{3} \mathrm{H}\right]$ arachidonic acid. PRP $(5.5 \mathrm{ml})$ was incubated for $15 \mathrm{~min}$ at $37^{\circ} \mathrm{C}$ with $6.25 \mu \mathrm{Ci}\left[{ }^{3} \mathrm{H}\right]$ arachidonic acid bound to $10 \%$ bovine serum albumin (essentially fatty acid free), thus permitting maximal incorporation of $\left[{ }^{3} \mathrm{H}\right]$ arachidonic acid into platelet membrane phospholipids, as described by Rittenhouse-Simmons et al. (18). The labeled PRP was gel-filtered to remove unincorporated $\left[{ }^{3} \mathrm{H}\right]$ arachidonic acid. After appropriate additions (plasmin and/or thrombin or ionophore A23187, as described below), the reacted platelet suspensions were pelleted by centrifugation at $8,700 \mathrm{~g}$ for $3 \mathrm{~min}$, and radioactivity released into the supernatant was counted.

High-performance liquid chromatography (HPLC) separation of arachidonic acid metabolites. In some experiments, the supernatants of the $\left[{ }^{3} \mathrm{H}\right]$ arachidonic acid release reactions were acidified to $\mathrm{pH} 3.0$ with citric acid and extracted three times with ethyl acetate. After evaporating the pooled ethyl acetate extracts under $\mathrm{N}_{2}$, the entire sample was injected in $50 \mu \mathrm{l}$ of methanol into a $4.6 \times 250 \mathrm{~mm}$ Ultrasphere ODS $5-\mu \mathrm{m}$ reverse-phase HPLC column (Altex Scientific, Inc., Berkeley, CA). All platelet arachidonic acid metabolites were separated as previously described (19), using increasing proportions of acetonitrile (30.5-95\%) in aqueous phosphoric acid (pH 2.0). The flow rate was $1.0 \mathrm{ml} / \mathrm{min}$. The column was equilibrated with $30.5 \%$ acetonitrile for $40 \mathrm{~min}$ before reuse. HPLC pumps (model 510; Waters Instruments Inc., Rochester, MN) with a programmable gradient system controller and a lambda-max LC spectrophotometer (model 481; Waters Instruments, Inc.) were used, and arachidonic acid metab- olites were measured by collection of $1.0-\mathrm{ml}$ fractions for radioactivity. Nonradioactive standards of $\mathrm{TXB}_{2}$ and 12-hydroxy-5,8,10,14-eicosatetraenoic acid were run simultaneously as elution markers.

Platelet cyclic AMP. Cyclic AMP in platelets was measured by radioimmunoassay, using $\left[{ }^{3} \mathrm{H}\right]$ cyclic AMP tracer (cyclic AMP assay kit, Amersham Corp., Arlington Heights, IL). The cyclic AMP assays were performed in trichloracetic acid extracts of the treated platelets after purification by ion-exchange chromatography (Dowex $50 \mathrm{~W}-\times 4$ 200-400 mesh hydrogen form; Bio-Rad Laboratories, Richmond, CA).

Materials. $\left[{ }^{3} \mathrm{H}\right]$ Arachidonic acid $(83.9 \mathrm{Ci} / \mathrm{mmol}),\left[{ }^{3} \mathrm{H}\right] \mathrm{TXB}_{2}(100-$ $150 \mathrm{Ci} / \mathrm{mmol}$ ), and $5-\left[2-{ }^{14} \mathrm{C}\right]$ hydroxytryptamine (serotonin) binoxalate (40-60 mCi/mmol) were obtained from New England Nuclear, Boston, MA. Purified human thrombin was kindly provided by Dr. Robert D. Rosenberg. Ionophore A23187 was purchased from Calbiochem-Behring Corp., American Hoechst Corp., San Diego, CA; collagen (Collagenreagent Horm) from Hormon-Chemie, Munich, Federal Republic of Germany; sodium arachidonate from Nu-Chek Prep., Inc., Elysian, MN; Sepharose 2B from Pharmacia Fine Chemicals, Inc., Uppsala, Sweden; $\mathrm{TXB}_{2}$ and $\mathrm{TXB}_{2}$ antiserum from the Upjohn Co., Kalamazoo, MI; plasmin and S-2288 chromogenic substrate from Kabi (AB) (Stockholm, Sweden) through Helena Laboratories, Beaumont, TX; and aprotinin and bovine serum albumin (essentially fatty acid-free) from Sigma Chemical Co., St. Louis, MO. Water used was deionized and filtered. All chemicals were reagent grade.

\section{Results}

Plasmin effect on platelet aggregation. Platelet aggregation in response to thrombin (1-5 $\mathrm{U} / \mathrm{ml}$ ), calcium ionophore $\mathrm{A} 23187$ $(3.5 \mu \mathrm{M})$, and collagen $(12.5 \mu \mathrm{g} / \mathrm{ml})$ was inhibited after preincubation of platelets with plasmin for $20 \mathrm{~min}$ at $37^{\circ} \mathrm{C}$. This plasmin-induced inhibition of platelet aggregation was dosedependent (Fig. 1), with complete inhibition noted at plasmin concentrations of $0.1-0.5 \mathrm{CU} / \mathrm{ml}$. In contrast, preincubation of platelets with plasmin at concentrations up to $0.5 \mathrm{CU} / \mathrm{ml}$ did not inhibit arachidonate-induced aggregation. There was only a slight dampening of the platelet aggregation response to arachidonate at $0.5 \mathrm{CU} / \mathrm{ml}$ plasmin. As shown in Fig. 2, the inhibition of thrombin-induced platelet aggregation by plasmin was also time-dependent, with complete inhibition of aggregation achieved within 10 min of plasmin preincubation at $37^{\circ} \mathrm{C}$. In contrast, plasmin preincubation for as long as 60 min had a minimal effect on arachidonate-induced aggregation.

Because high concentrations of plasmin have been previously reported to induce platelet aggregation and release (6), we examined the direct effect of plasmin on platelet activation. At concentrations up to $0.5 \mathrm{CU} / \mathrm{ml}$, plasmin alone did not directly stimulate platelet shape change, aggregation, or serotonin release.

Plasmin effect on platelet thromboxane synthesis. The production of platelet thromboxane (measured by radioimmunoassay of $\mathrm{TXB}_{2}$ ) stimulated by thrombin, ionophore A23178, and collagen was blocked by preincubation of platelets with plasmin (Table I). The plasmin inhibition of $\mathrm{TXB}_{2}$ synthesis was clearly noted at concentrations above $0.05 \mathrm{CU} /$ ml. Plasmin maximally inhibited thrombin-induced $\mathbf{T X B}_{2}$ production by $95 \%$, although it maximally inhibited ionophoreinduced release by only $58 \%$; the extent of inhibition of collagen-induced $\mathrm{TXB}_{2}$ production was intermediate. The concentration-dependent inhibitory effects of plasmin on platelet aggregation and $\mathrm{TXB}_{2}$ formation in response to these three agents were approximately parallel. In contrast, consistent with its lack of effect on arachidonate-induced aggregation, plasmin at concentrations up to $0.5 \mathrm{CU} / \mathrm{ml}$ did not inhibit arachidonateinduced $\mathrm{TXB}_{2}$ production (Table I). 


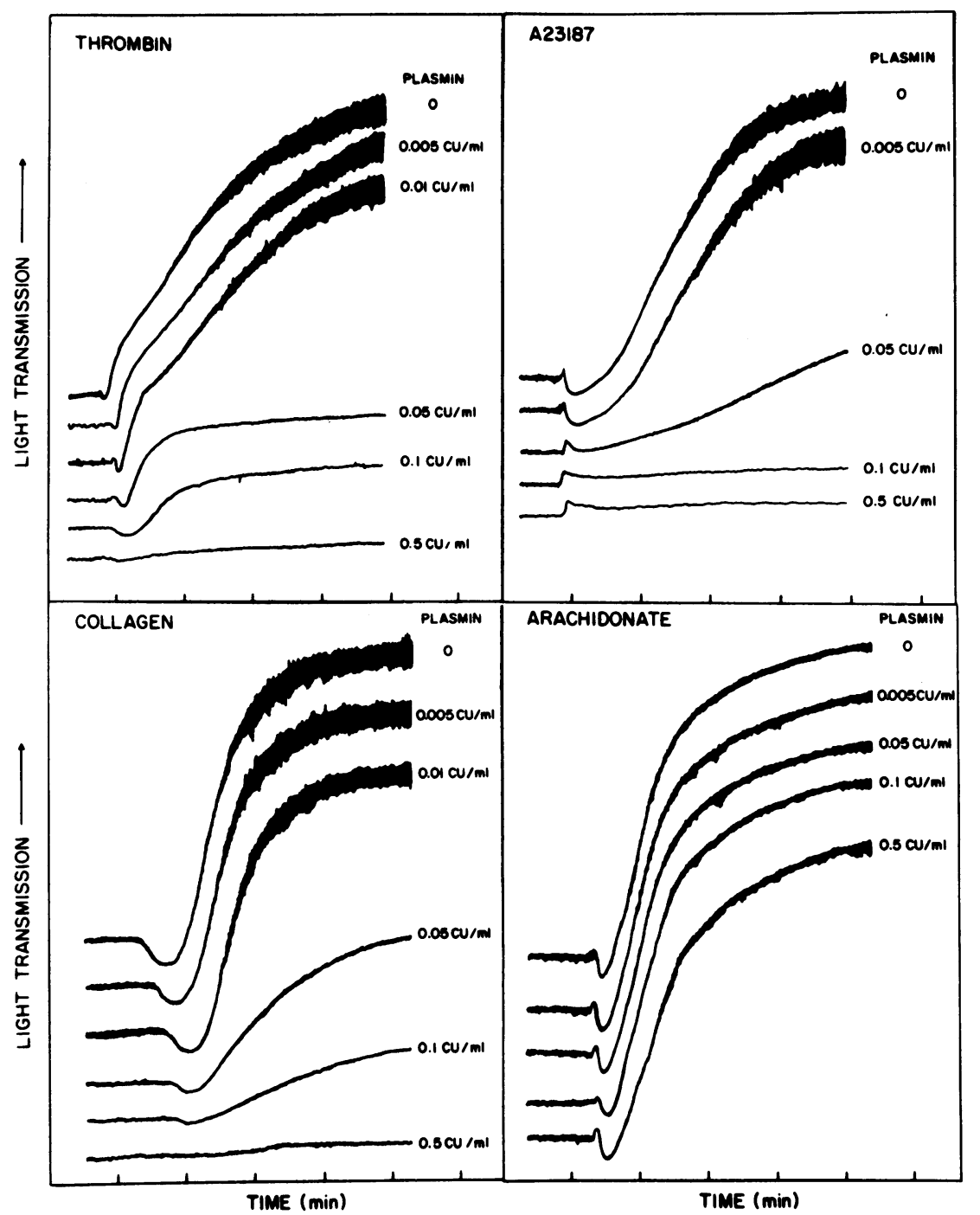

Figure 1. Effect of plasmin on platelet aggregation induced by thrombin, ionophore A23187, collagen, and arachidonate. Gel-filtered platelets were preincubated with various concentrations of plasmin $(0-0.5 \mathrm{CU} / \mathrm{ml})$ for $20 \mathrm{~min}$ at $37^{\circ} \mathrm{C}$ in a shaking water bath. After the addition of aprotinin (1.7 trypsin inhibitor units [TIU]/ml, final concentration) and calcium (3 $\mathrm{mM}$, final concentration), aggregation was initiated by thrombin $(1 \mathrm{U} / \mathrm{ml})$, ionophore A23187 $(3.5 \mu \mathrm{M})$, collagen $(12.5 \mu \mathrm{g} / \mathrm{ml})$, or arachidonate $(0.38 \mathrm{mM})$. Aprotinin alone did not inhibit platelet aggregation.
Plasmin effect on platelet arachidonic acid release. The discrepancy between plasmin's inhibition of thrombin-, ionophore-, and collagen-induced aggregation and $\mathrm{TXB}_{2}$ production and its lack of inhibition of arachidonate-induced aggregation and $\mathrm{TXB}_{2}$ production suggests that plasmin may exert its effects by blocking mobilization of endogenous arachidonic acid from platelet membrane phospholipid pools. To examine this possibility, we studied the effect of plasmin on platelet oxygen consumption. The platelet oxygen burst is entirely a function of arachidonic acid oxygenation $(20,21)$. When

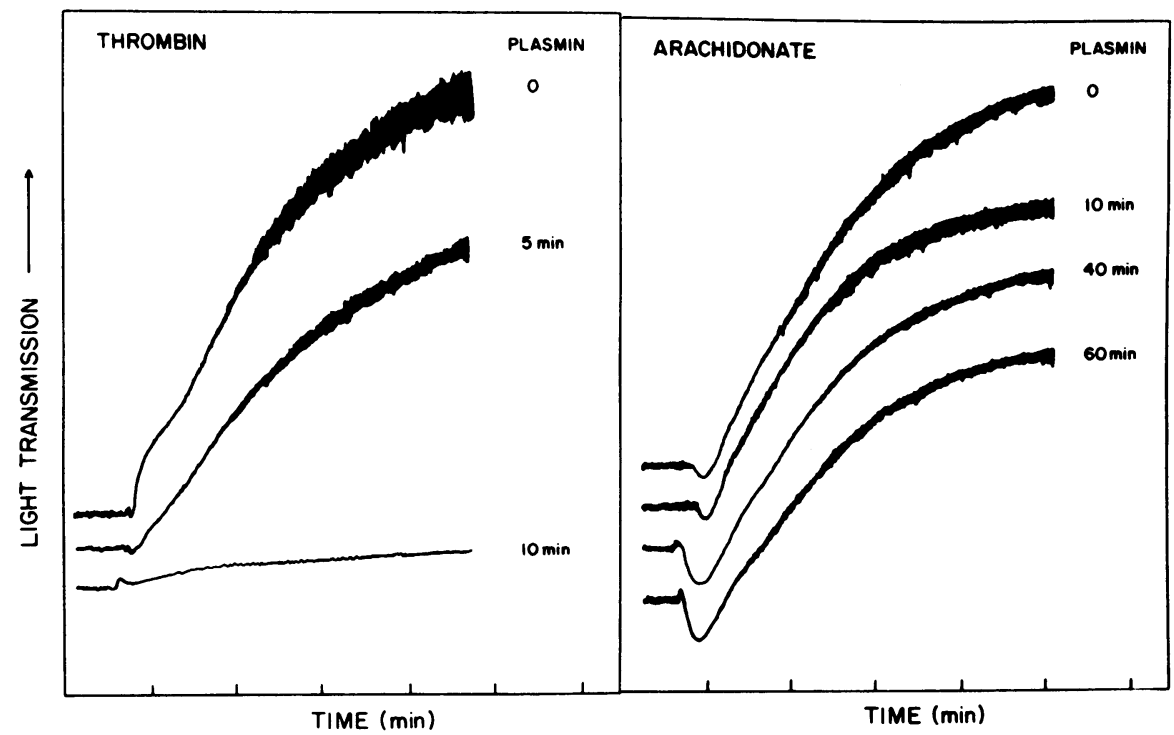

Figure 2. Time dependence of plasmin preincubation on inhibition of thrombinand arachidonate-induced platelet aggregation. Gel-filtered platelets were preincubated with $0.5 \mathrm{CU} / \mathrm{ml}$ plasmin at $37^{\circ} \mathrm{C}$ in a shaking water bath. After various time periods of incubation, as indicated, aliquots were transferred to aggregometer cuvettes containing aprotinin (1.7 TIU/ml, final concentration). Aggregation was initiated by thrombin (1 U/ $\mathrm{ml}$ ) or arachidonate $(0.38 \mathrm{mM})$. 
Table I. Plasmin Inhibition of Thrombin, Ionophore A23187, Collagen, and Arachidonate-stimulated Platelet Thromboxane Production

\begin{tabular}{lllll}
\hline \multirow{2}{*}{$\begin{array}{l}\text { Plasmin } \\
\text { concentration }\end{array}$} & \multicolumn{4}{l}{ Thromboxane $\mathrm{B}_{2}\left(\mathrm{pg} / 10^{6}\right.$ platelets) } \\
\cline { 2 - 5 } Thrombin & A23187 & Collagen & Arachidonate \\
\hline CU/ml & & & & \\
0 & $575.3 \pm 19.7$ & $686.2 \pm 11.1$ & $877.7 \pm 31.7$ & $1,765.6 \pm 35.7$ \\
0.005 & $545.7 \pm 16.6$ & $654.4 \pm 6.5$ & $704.5 \pm 24.8$ & $1,527.5 \pm 174.1$ \\
0.05 & $184.7 \pm 12.7$ & $385.6 \pm 11.4$ & $413.3 \pm 16.0$ & $1,513.5 \pm 32.9$ \\
0.1 & $69.8 \pm 3.5$ & $291.6 \pm 13.7$ & $312.9 \pm 6.0$ & $1,779.8 \pm 61.3$ \\
0.5 & $26.7 \pm 0.3$ & $392.9 \pm 11.6$ & $273.4 \pm 5.5$ & $1,877.5 \pm 90.2$
\end{tabular}

Gel-filtered platelets were preincubated with various concentrations of plasmin $(0-0.5 \mathrm{CU} / \mathrm{ml})$ for $20 \mathrm{~min}$ at $37^{\circ} \mathrm{C}$. After the addition of aprotinin (1.7 TIU/ml), TXB 2 production was stimulated by thrombin $(1 \mathrm{U} / \mathrm{ml})$, ionophore A23187 (3.5 $\mu \mathrm{M})$, collagen $(12.5 \mu \mathrm{g} / \mathrm{ml})$, or arachidonate $(0.38 \mathrm{mM})$. TXB 2 was measured by radioimmunoassay of supernatants of 4-min reactions with these agents. Data are mean \pm SEM of quadruplicate measurements representing two experiments.

stimulated by thrombin, ionophore, or collagen, the platelet oxygen burst depends on both endogenous arachidonic acid release by phospholipases and the actual oxygen consuming arachidonic acid oxygenases; when directly stimulated by exogenous arachidonate, the platelet oxygen burst is an index of oxygenation only (22). As shown in Fig. 3, plasmin preincubation almost entirely abolished the thrombin-induced platelet oxygen burst (from a maximal rate of $20 \mathrm{nAtoms} / \mathrm{min}$ in the control reaction to $3 \mathrm{nAtoms} / \mathrm{min}$ in the plasmintreated reaction). In contrast, plasmin had no effect on the arachidonate-induced oxygen burst (13 nAtoms/min in both the control and plasmin-treated reactions).

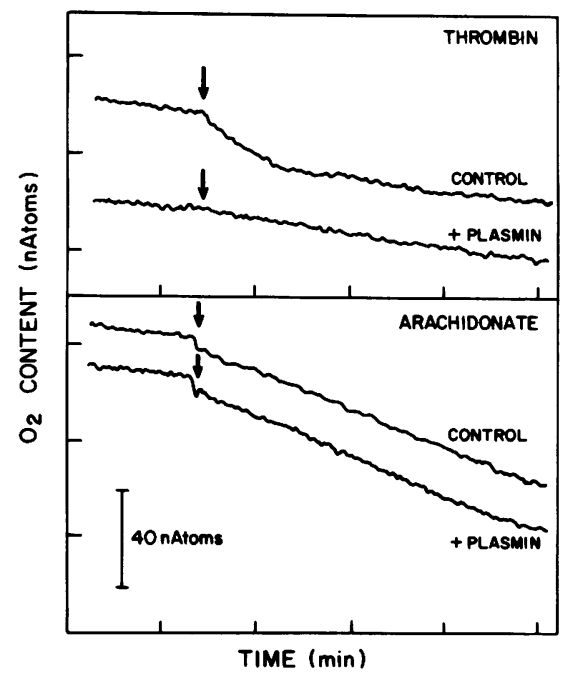

Figure 3. Effect of plasmin on platelet oxygen consumption. Gelfiltered platelets were preincubated with $(0.1 \mathrm{CU} / \mathrm{ml})$ or without plasmin for $20 \mathrm{~min}$ at $37^{\circ} \mathrm{C}$. After the addition of aprotinin $(1.7$ $\mathrm{TIU} / \mathrm{ml}$ ), the oxygen burst was initiated at the points of the arrows by thrombin $(2 \mathrm{U} / \mathrm{ml})$ or arachidonate $(50 \mu \mathrm{M})$. The slope of declining oxygen content in the chamber before stimulus addition represents basal oxygen consumption. Aprotinin alone did not inhibit the oxygen burst.
To directly demonstrate the inhibitory effect of plasmin on arachidonic acid mobilization, platelets were incubated with $\left[{ }^{3} \mathrm{H}\right]$ arachidonic acid to label membrane phospholipid pools and then stimulated with thrombin or ionophore A23187 to induce arachidonic acid release. As shown in Table II, plasmin preincubation inhibited the thrombin-induced release of arachidonic acid by $\sim 50 \%$. However, ionophore-induced arachidonic acid release was not inhibited by plasmin.

When the metabolic products of the thrombin-induced release of arachidonic acid were analyzed by HPLC, the formation of cyclooxygenase and lipoxygenase metabolites were found to be comparably affected by plasmin. Plasmin preincubation reduced the formation of $\left[{ }^{3} \mathrm{H}\right] \mathrm{TXB}_{2}$ (the major cyclooxygenase metabolite) by $75.4 \%$ and 12 -hydroxy-5,8,10,14eicosatetraenoic acid (the major lipoxygenase metabolite) by $64.2 \%$.

Since these results suggest that plasmin inhibits platelet function and arachidonic acid metabolism by blocking endogenous arachidonic acid mobilization, the effects of plasmin on platelet cyclic AMP were determined. As shown in Table III, prostaglandin $\mathrm{I}_{2}\left(\mathrm{PGI}_{2}\right)$ and prostaglandin $\mathrm{E}_{1}\left(\mathrm{PGE}_{1}\right)$, known stimulators of platelet adenylate cyclase and inhibitors of arachidonic acid release, raised cyclic AMP concentrations approximately sixfold over basal levels; this effect was markedly enhanced by the phosphodiesterase inhibitor theophylline. However, plasmin failed to raise platelet cyclic AMP even in the presence of theophylline.

\section{Discussion}

In this study, we report that plasmin causes a dose- and timedependent inhibition of platelet aggregation in response to thrombin, calcium ionophore, and collagen, but not in response to arachidonic acid. These functional effects are paralleled by inhibitory effects of plasmin on net platelet thromboxane production. Plasmin is found to exert this action, at least in part, by blocking the mobilization of endogenous arachidonic acid from platelet membrane pools without inhibiting the further metabolism of free arachidonic acid.

Platelet aggregation depends upon the binding of fibrinogen to surface receptors (23). The inhibition of platelet aggregation

Table II. Plasmin Inhibition of Thrombin- and Ionophore A23187-induced Release of $\left[{ }^{3} \mathrm{H}\right]$ Arachidonic Acid

\begin{tabular}{lll}
\hline $\begin{array}{l}\text { Plasmin, } \\
10 \text { min }\end{array}$ & $\begin{array}{l}\text { Stimulus, } \\
20 \text { min }\end{array}$ & Percent ['H]AA released \\
\hline- & - & $1.8 \pm 0.1$ \\
+ & - & $2.8 \pm 0.1$ \\
- & Thrombin & $20.2 \pm 0.3$ \\
+ & Thrombin & $10.8 \pm 0.2$ \\
- & A23187 & $25.2 \pm 0.1$ \\
+ & A23187 & $25.1 \pm 0.2$ \\
\hline
\end{tabular}

Platelet membrane phospholipids were labeled with $\left[{ }^{3} \mathrm{H}\right]$ arachidonic acid $\left(\left[{ }^{3} \mathrm{H}\right] \mathrm{AA}\right)$, gel-filtered to eliminate unincorporated radioactivity, and then incubated at $37^{\circ} \mathrm{C}$ with or without plasmin for $10 \mathrm{~min}$, followed either by no further additions, thrombin $(2 \mathrm{U} / \mathrm{ml})$, or ionophore A23187 (3.5 $\mu \mathrm{M})$ for an additional $20 \mathrm{~min}$. Radioactivity released into the supernatant was counted. Data are mean \pm SEM of quadruplicate measurements representing two separate experiments. 
Table III. Effect of Plasmin and Prostaglandins on Platelet Cyclic AMP

\begin{tabular}{lcc}
\hline & \multicolumn{2}{c}{ Cyclic AMP (pmol/10 $0^{8}$ platelets) } \\
\cline { 2 - 3 } Addition & No theophylline & + Theophylline \\
\hline 0 & 7.5 & 7.0 \\
Plasmin $(0.1 \mathrm{CU} / \mathrm{ml})$ & 6.0 & 10.0 \\
Plasmin $(1.0 \mathrm{CU} / \mathrm{ml})$ & 6.0 & 8.0 \\
PGI $_{2}(10 \mu \mathrm{M})$ & 48.0 & 332.0 \\
PGE $_{1}(10 \mu \mathrm{M})$ & 42.0 & 120.0 \\
\hline
\end{tabular}

Gel-filtered platelets, preincubated with or without theophylline (10 $\mathrm{mM})$ for $10 \mathrm{~min}$ at $37^{\circ} \mathrm{C}$, were reacted with plasmin $(0.1 \mathrm{CU} / \mathrm{ml}$ or $1.0 \mathrm{CU} / \mathrm{ml}), \mathrm{PGI}_{2}(10 \mu \mathrm{M}), \mathrm{PGE}_{1}(10 \mu \mathrm{M})$, or buffer blank for $5 \mathrm{~min}$ at $37^{\circ} \mathrm{C}$. Reactions were terminated by the addition of equal volumes of ice-cold $10 \%$ trichloracetic acid, and samples were extracted for measurement of cyclic AMP by radioimmunoassay as described in Methods. Data are means of duplicate determinations, representative of two separate experiments.

by plasmin at the low concentrations used in this study is unlikely to be due to plasmin-induced release of platelet fibrinogen and its subsequent digestion by plasmin (6). Almost complete inhibition of platelet aggregation was found in response to thrombin, ionophore, and collagen by plasmin at concentrations that did not directly affect shape change, aggregation, or release. Furthermore, plasmin was unlikely to have its effect on extracellular fibrinogen, since washed platelets suspended in fibrinogen-free buffer were used. Plasmin did not digest fibrinogen released from platelets after stimulation by thrombin, ionophore, or collagen, since plasmin was completely inactivated with aprotinin before addition of the aggregating agent. Aprotinin itself had no effect on platelet aggregation. Finally, plasmin pretreatment at these lower concentrations did not inhibit arachidonate-induced platelet aggregation. If plasmin degradation of fibrinogen were the mechanism of its inhibitory action on platelets, it would also be expected to block arachidonate-induced aggregation. Patients with Glanzmann's thrombasthenia, whose platelets lack surface receptors for fibrinogen, demonstrate a markedly impaired aggregation response to arachidonate as well as to the other aggregating agents (24). Therefore, the mechanism of plasmin inhibition of platelet aggregation observed in our studies is unlikely to be due to the digestion of fibrinogen by plasmin.

Paralleling the plasmin dose-dependent inhibition of platelet aggregation, we found marked inhibition of platelet thromboxane production in response to thrombin, ionophore, and collagen. In contrast, as with its lack of effect on arachidonateinduced aggregation, plasmin failed to inhibit arachidonateinduced thromboxane formation. The discrepancy between thrombin, ionophore, and collagen responses on the one hand and arachidonate response on the other, suggested that plasmin may exert its inhibitory effect on mobilization of endogenous arachidonic acid from platelet membrane phospholipid pools. This was confirmed by two additional experimental approaches. First, plasmin was found to almost completely block the thrombin-induced platelet oxygen burst, which depends on both endogenous arachidonic acid release by thrombin and its subsequent oxygenation. In contrast, plasmin had no effect on the arachidonate-induced oxygen burst, which is an index of oxygenation only (21). Second, we directly examined the effect of plasmin on the thrombin-induced hydrolysis of free arachidonic acid after labeling platelet membrane phospholipids with $\left[{ }^{3} \mathrm{H}\right]$ arachidonic acid. Plasmin inhibited arachidonic acid release by $\sim 50 \%$ but did not inhibit the subsequent metabolism of arachidonic acid by either the cyclooxygenase or the lipoxygenase pathway. It is of interest that, while plasmin pretreatment of the platelets inhibited thrombin-induced arachidonate release, it did not affect ionophore-induced release. The inhibitory effect of plasmin on thrombin-induced $\mathrm{TXB}_{2}$ production was also more marked than on ionophore-induced $\mathrm{TXB}_{2}$ production (Table I). These data suggest that the effect of plasmin on arachidonic acid mobilization may be a complex one, possibly inhibiting thrombin-activated phosphatidylinositol-specific phospholipase C preferentially over an effect on ionophore A23187-activated phospholipase A (25).

Our data suggest that plasmin inhibits platelet function, at least in part, by blocking the mobilization of arachidonic acid from membrane phospholipids in response to phospholipase activators. Plasmin may exert its effect either by the inactivation of platelet phospholipase(s) or by the depletion of precursor pools of arachidonic acid esterified to membrane phospholipids. The latter mechanism has been noted in thrombin-treated platelets, in which a reduction of the arachidonic acid content of phosphatidylinositol has been found $(26,27)$. This has been proposed as a likely explanation for the finding of decreased thromboxane formation from endogenous arachidonic acid in thrombin-pretreated platelets (28). In this latter study, cyclooxygenase activity of thrombin-treated platelets was preserved, similar to our observations with plasmin-treated platelets. Furthermore, since the plasmin-inhibited platelet activities noted in this study are calcium-dependent, it is possible that plasmin also exerts its inhibitory effects on platelets by impairing the membrane binding or translocation of free calcium.

Since platelet arachidonic acid mobilization is inhibited by agents that raise intracellular levels of cyclic $\operatorname{AMP}(29,30)$, we examined the effect of plasmin on platelet cyclic AMP content. Unlike known activators of adenylate cyclase $\left(\mathrm{PGI}_{2}\right.$ and $\left.P G E_{1}\right)$, plasmin failed to increase platelet cyclic AMP, even in the presence of a phosphodiesterase inhibitor, precluding this action as the mechanism of plasmin inhibition of arachidonic acid mobilization.

The important question of whether the concentration of plasmin found to inhibit platelet function and arachidonic acid metabolism in our studies is attainable in pathologic or pharmacologic states of fibrinolysis is difficult to resolve. Alpha-2-antiplasmin is the major physiologic inhibitor of plasmin, and it acts rapidly to bind and inactivate any free plasmin that may be released into the plasma. However, in severe liver disease or disseminated intravascular coagulation and during thrombolytic therapy with streptokinase, alpha-2antiplasmin is consumed, and biologically active plasmin circulates (31-33). More important, the amounts of free plasmin generated locally at the site of clot formation are likely to be the critical modulators of platelet function. Plasmin molecules bound to fibrin and involved in fibrin degradation are protected from rapid inactivation by alpha-2-antiplasmin (34) but could still be effective in inhibiting platelets. Activation of plasmin on the surface of the injured vessel wall could also have localized effects on platelets in its proximity (8). Finally, enhanced and locally concentrated plasmin may generate on the surfaces of activated platelets that bind plasminogen within thrombi (5). 
Conceptually, in a manner analogous to the reciprocal activation of thrombin and platelets to promote clot formation at sites of vascular injury, plasmin and platelets may interact to promote and amplify clot dissolution. Considerably more in vitro and in vivo studies are required to elucidate these complex interactions. This study suggests the possibility that local plasmin generation may inhibit the further accrual of platelets into a developing thrombus. Therefore, platelets may be important targets of physiologic, pathologic, and pharmacologic fibrinolysis.

\section{Acknowledgments}

The authors are grateful to Dr. Robert I. Handin and Dr. Jack Hawiger for helpful discussions, Ms. Sheila Farrell for excellent technical assistance, and Ms. Linda Lyster for preparation of the manuscript.

This work was supported by National Institutes of Health grant HL-27465, a grant-in-aid from the American Heart Association with funds contributed in part by the Massachusetts Affiliate, and the William F. Milton Fund.

\section{References}

1. Taylor, F. B., Jr., and J. H. Muller-Eberhard. 1970. Qualitative description of factors involved in the retraction and lysis of dilute whole blood clots and in aggregation and retraction of platelets. $J$. Clin. Invest. 49:2068-2085.

2. Lockhart, M., P. C. Comp, and F. B. Taylor, Jr. 1979. Role of platelets in lysis of dilute plasma clots: requirement for metabolically active platelets. J. Lab. Clin. Med. 94:285-294.

3. Carroll, R. C., J. M. Gerrard, and J. M. Gilliam. 1981. Clot retraction facilitates clot lysis. Blood. 57:44-48.

4. Carroll, R. C., R. D. Radcliffe, F. B. Taylor, Jr., and J. M. Gerrard. 1982. Plasminogen, plasminogen activator, and platelets in the regulation of clot lysis. J. Lab. Clin. Med. 100:986-996.

5. Miles, L. A., and E. P. Plow. 1984. Platelets bind plasminogen and potentiate its activation. Haemostasis. 14:48.

6. Niewiarowski, S., A. F. Senyi, and P. Gillies. 1973. Plasmininduced platelet aggregation and platelet release reaction. J. Clin. Invest. 52:1647-1659.

7. Greenberg, J. P., M. A. Packham, M. A. Guccione, M. L. Rand, H.-J. Reimers, and J. F. Mustard. 1979. Survival of rabbit platelets treated in vitro with chymotrypsin, plasmin, trypsin, or neuraminidase. Blood. 53:916-927.

8. Winocour, P. D., R. L. Kinlough-Rathbone, M. Richardson, and J. F. Mustard. 1983. Reversal of shortened platelet survival in rats by the antifibrinolytic agent, epsilon aminocaproic acid. J. Clin. Invest. 71:159-164.

9. Adelman, B., A. D. Michelson, J. Loscalzo, J. Greenberg, and R. I. Handin. 1984. Plasmin effect on platelet glycoprotein Ib-von Willebrand's factor interaction. Blood. In press.

10. Miller, J. L., A. J. Katz, and M. B. Feinstein. 1975. Plasmin inhibition of thrombin-induced platelet aggregation. Thromb. Diath. Haemorrh. 33:286-309.

11. Squouris, J. T., J. K. Inman, K. B. McCall, L. A. Hyndman, and H. D. Anderson. 1960. The preparation of human fibrinolysin (plasmin). Vox Sang. 5:357-376.

12. Friberger, P., M. Knos, S. Gustavsson, L. Aurell, and G. Claeson. 1979. A new specific substrate for the determination of plasmin activity. In Chromogenic Peptide Substrates. M. F. Scully and V. V. Kakkar, editors. Churchill Livingstone, London.

13. Kabi Diagnostica Data Sheet for S-2288.

14. Born, G. V. R., and M. J. Cross. 1963. The aggregation of blood platelets. J. Physiol. (Lond.). 168:178-195.
15. Jerushalmy, W., and M. B. Zucker. 1966. Some effects of fibrinogen degradation products (FDP) or blood platelets. Thromb. Diath. Haemorrh. 15:413-419.

16. Costa, J. L., and D. L. Murphy. 1975. Platelet 5-HT uptake and release stopped rapidly by formaldehyde. Nature (Lond.). 255:407408.

17. Murer, E. H. 1968. Release reaction and energy metabolism in blood platelets with special reference to the burst of oxygen uptake. Biochim. Biophys. Acta. 162:320-326.

18. Rittenhouse-Simmons, S., F. A. Russell, and D. Deykin. 1976. Transfer of arachidonic acid to human platelet plasmalogen in response to thrombin. Biochem. Biophys. Res. Commun. 70:295-301.

19. Van Rollins, M., S. H. K. Ho, J. E. Greenwald, M. Alexander, N. J. Dorman, L. K. Wong, and L. A. Horrocks. 1980. Complete separation by high-performance liquid chromatography of metabolites of arachidonic acid from incubation with human and rabbit platelets. Prostaglandins. 20:571-577.

20. Hamberg, M., J. Svensson, and B. Samuelsson. 1975. Thromboxanes: a new group of biologically active compounds derived from prostaglandin endoperoxides. Proc. Natl. Acad. Sci. USA. 72:29942998.

21. Marcus, A. J. 1979. Pathways of oxygen utilization by stimulated platelets and leukocytes. Semin. Hematol. 16:188-195.

22. Bressler, N. M., M. J. Broekman, and A. J. Marcus. 1979. Concurrent studies of oxygen consumption and aggregation in stimulated human platelets. Blood. 53:167-178.

23. Vermylen, J., P. N. Badenhorst, H. Deckmyn, and J. Arnout. 1983. Normal mechanisms of platelet function. Clin. Haematol. 12:107151.

24. Malmsten, C., H. Kindahl, B. Samuelsson, S. Levy-Toledano, G. Tobelem, and J. P. Caen. 1977. Thromboxane synthesis and the platelet release reaction in Bernard-Soulier syndrome, thrombasthenia Glanzmann and Hermansky-Pudlak syndrome. Br. J. Haematol. 35:511-520.

25. Rittenhouse-Simmons, S. 1981. Differential activation of platelet phospholipases by thrombin and ionophore A23187. J. Biol. Chem. 256:4153-4155.

26. Prescott, S. M., and P. W. Majerus. 1981. The fatty acid composition of phosphatidylinositol from thrombin-stimulated human platelets. J. Biol. Chem. 256:579-582.

27. Imai, A., K. Yano, Y. Kameyama, and Y. Nozawa. 1981. Reversible thrombin-induced modification of positional distribution of fatty acids in platelet phospholipids: involvement of deacylationreacylation. Biochem. Biophys. Res. Commun. 103:1092-1099.

28. Reimers, H.-J., R. E. Scharf, and R. K. Baker. 1984. Thrombin pretreatment of human platelets impairs thromboxane $A_{2}$ synthesis from endogenous precursors in the presence of normal cyclooxygenase activity. Blood. 63:858-865.

29. Minkes, M., N. Stanford, M. M.-Y. Chi, G. J. Roth, A. Raz, P. Needleman, and P. W. Majerus. 1977. Cyclic adenosine 3',5'monophosphate inhibits the availability of arachidonate to prostaglandin synthetase in human platelet suspensions. J. Clin. Invest. 59:449-454.

30. Lapetina, E. G., C. J. Schmitges, K. Chandrabose, and P. Cuatrecasas. 1977. Cyclic adenosine 3',5'-monophosphate and prostacyclin inhibit phospholipase activity in platelets. Biochem. Biophys. Res. Commun. 76:828-835.

31. Collen, D. 1980. On the regulation and control of fibrinolysis Thromb. Haemostasis. 43:77-89.

32. Teger-Nilsson, A. C., P. Friberger, and E. Gyzander. 1977. Determination of a new rapid plasmin inhibitor in human blood by means of a plasmin specific tripeptide substrate. Scand. J. Clin. Lab. Invest. 37:403-409.

33. Verstraete, M., J. Vermylen, and J. Schetz. 1978. Biochemical changes noted during intermittent administration of streptokinase. Thromb. Haemostasis. 39:61-68.

34. Wiman, B., and D. Collen. 1978. Molecular mechanism of physiologic fibrinolysis. Nature (Lond.). 272:545-550. 